\title{
Soil resistance in the process of dams' irrigation canals profiling
}

\author{
Alexander Apalkov ${ }^{1}$, Sergey Apalkov ${ }^{2}$, Sergey Kuren ${ }^{1}$, Sergey Popov ${ }^{1, *}$ and Nikolai Dontsov ${ }^{1}$ \\ ${ }^{1}$ Don State Technical University, 1, Gagarin sq., 344003, Rostov on Don, Russia \\ ${ }^{2}$ Don State Agrarian University, 111, Pushkinskaya st., 346428, Novocherkassk, Russia
}

\begin{abstract}
The questions of processing technology of dam channels using appropriate mechanisms are presented taking into account the requirements of modern engineering hydrology. Channel profiling with the best quality and performance can be carried out by means of mechanization at the expense of working tools, able to process not only longitudinal but also cross-sections of channels. According to calculations, there was established, that the best condition for moving soil on the channel slope in front of the passive knife, is an equable distribution along the slope. It was marked, that the strength of the soil pressure is most affected by the installation value of the trowel knife and the thickness of the loosened soil layer to be compacted. Recommendations on increasing the active working body stability of the dam profiler are given.
\end{abstract}

\section{Introduction}

Reclaimed lands are the main link in the agricultural production stabilization. Worldwide irrigated land area is about 270 million hectares, of which in India - 21\%; in China $-17.7 \%$; in the USA $-9.3 \%$, and Russia accounts for $1.6 \%$. In the world, the area of drained lands is -200 million hectares, of which the United States owns a share of such territories $30 \%$; China $-3.4 \%$; India $-31 \%$; Russia $-2.4 \%$.

Today, only 1.5 million hectares of reclaimed land are effectively used. In Russia there are many regions with adverse climatic conditions. These are permafrost zones, mountain ranges and arid steppe zones. For example, the USA, where less than $400 \mathrm{~mm}$ of precipitation falls annually, is less than $2 \%$, and in Russia $-40 \%$, the share of 6 farmland with rainfall of $700 \mathrm{~mm}$ or more in the USA is $60 \%$, and in Russia only $11 \%$.

In the new land use conditions, many parameters of the further development of irrigation systems have been revised. The issues of irrigation systems technical level improving, the reliability and environmental friendliness of its work have come to the fore. The issues of irrigation systems operation, water supply and water distribution management are examined in a new way. [1-14]. Land reclamation, in general, and irrigation systems, in particular, are the most powerful environmental transforming factors and can lead to negative environmental consequences in this region.

Currently, for profiling the dams' surface of irrigation canals, planning works use machines that are not intended to perform these works, or machines that have low

\footnotetext{
* Corresponding author: spopov1957@yandex.ru
} 
productivity. This direction is not sufficiently studied, therefore its relevance is not in doubt.

As a basic machine, we can take a machine with an optimal working width, equal to the dam cross section perimeter, since the most promising is the use of machines for profiling by increasing the working tool width. Such arrangement of profiler working tool, relative to the base machine is most successful, since the traction resistance during profiling will be evenly spaced. The scheme of channel dams' surface profiling by machines with working body symmetrical arrangement facilitates the constructive decision of the profiler and allows more efficient use of the base truck power.

In order to increase the speed of mechanization means movement for channel maintenance and increase canal repair machines productivity during deformation of the dam crest, scientific studies have been carried out to improve the working conditions of machines that reduce water loss from filtering due to channel profiling.

The main requirement for the newly created reclamation machines for the care of irrigation canals should be ensuring high productivity when processing canals' dams using various working tools, capable of processing not only longitudinal but also cross-sections of channels.

\section{Theoretical studies}

The surface of irrigation canals dams consists of horizontal section - dam crest and two inclined surfaces - external and internal slopes. In the ideal case, the above channel surfaces represent planes located at certain angles to the horizon.

Let us consider the uneven damsэ microrelief to be aligned, in a plane, perpendicular to the surface under study and parallel to the longitudinal axis of the dam. Perfectly aligned surface in the measurement plane represents a straight line crossing the wavy microprofile in such a way, that the area of soil protrusions located above it, is equal to the area of depressions located below the line.

In this case, when leveling the surface with minimal energy consumption, it is necessary to move such an amount of soil, that the resulting surface is smooth, i.e. closely matched the perfect surface.

The average linear deviation from the absolute values midline of plot surface microprofile ordinates, measured at intervals $\Delta \ell$, is

$$
\Delta h=\sqrt{\frac{1}{n} \sum_{i=1}^{n}\left(h_{i}-h_{c u t}\right)^{2}},
$$

where $\mathrm{h}_{\text {cut }}$ - midline ordinate, $\mathrm{cm}$;

$\mathrm{h}_{\mathrm{i}}$ - microprofile current ordinate, $\mathrm{cm}$;

$n$ - number of measurements.

Making an assumption, that the obtained microprofile of the surface of the channels in the studied plane is constant for a certain section of width $B$ and length $L$ we get

$$
V_{c u t}=V_{b f}=B \cdot L \cdot \sqrt{\frac{1}{n} \sum_{i=1}^{n}\left(h_{i}-h_{c u t}\right)^{2}},
$$

where $V_{c u t}$ - volume of soil to be cut, $\mathrm{m}^{2}$; 
$V_{b f}$ - soil volume required for backfilling, $\mathrm{m}^{2}$.

Due to the fact that the soil has a high density before destruction, replace in the formula $\mathrm{V}_{\mathrm{bf}}=\mathrm{V}_{c u t} \cdot K_{d}$ and, making the necessary transformations, determine the volume of soil to be cut during alignment of the channel dam section

$$
V_{c u t}=\frac{K_{d}}{\left(1+K_{d}\right)} \cdot B \cdot L \cdot \sqrt{\frac{1}{n} \sum_{i=1}^{n}\left(h_{i}-h_{c u t}\right)^{2}},
$$

analogically

$$
V_{b f}=\frac{K_{d}}{\left(1+K_{d}\right)} \cdot B \cdot L \cdot \sqrt{\frac{1}{n} \sum_{i=1}^{n}\left(h_{i}-h_{c u t}\right)^{2}}
$$

In the obtained formulas, the linear deviation average of the microprofile ordinates' absolute values from the midline of an arbitrarily selected section can be considered as a random process. Therefore, for practical calculations, it is more convenient to use the standard deviation of the irregularities from the midline $\sigma_{\mathrm{h}}^{\text {cut }}$ «typical» dams' surface, defined by set $\sigma_{h}$, i.e

$$
\sigma_{\mathrm{h}}^{c u t}=\frac{1}{n} \sum_{1}^{n} \sigma_{h}^{i}
$$

where $\sigma_{h}^{i}$-standard deviation of the plot irregularities;

$n$ - number of study sites.

In order to ensure minimum energy intensity of the dams surface leveling process, the geometric parameters of the equalizer working tool should be such, so that in the work process we can transport the minimum necessary amount of soil, the value of which can be determined

$$
V_{p r}=\frac{K_{d}}{\left(1+K_{d}\right)} \cdot B^{\prime} \cdot \ell \cdot \sigma_{h}^{c u t}
$$

where $B^{\prime}$ - width of the surface, processed by working tool, m;

$\ell$ - length of drawing prism base, measured perpendicular to the cutting edge.

\section{Results and discussion}

Studies of microprofile irregularities of the channel dams' surface profile to be profiled have been conducted. These studies show that for both types of selected surfaces, the statistical parameters' average values of the studied dam surfaces, as well as parameters of the averaged correlation functions and spectral densities, obtained from the functions realizations ensemble describing the microprofiles irregularities of the channel dams studied surfaces, can serve as averaged statistical characteristics. 
The revealed statistical characteristics of channels surface irregularities distribution represent direct material not only for the design of machines, and for:

- determining the soil volume that needs to be moved from high places to low ones when leveling dams surface;

- creating simulation conditions and operating modes in laboratory and experimental studies of channel-repair machines working tools;

- determining the basic geometric parameters of canal repair machines working tools;

- development of technology for the application and establishment of differentiated agrotechnical tolerances for operations performed by a complex of machines for irrigation canals care.

Taking into account the stated requirements, calculation of the resistance to passive and trowel knives movement and justification of dam profiler combined working tool parameters were carried out.

\section{Passive knife movement resistance}

With the steady process of profiling, the combined working tool passive knife of profiler moves a certain mass of soil $G_{h}$, necessary for swamping on dam troughs treated surface. Therefore, the force, required to determine the resistance forces to the movement of the passive knife will be spent on moving the loosened soil (Figure 1).

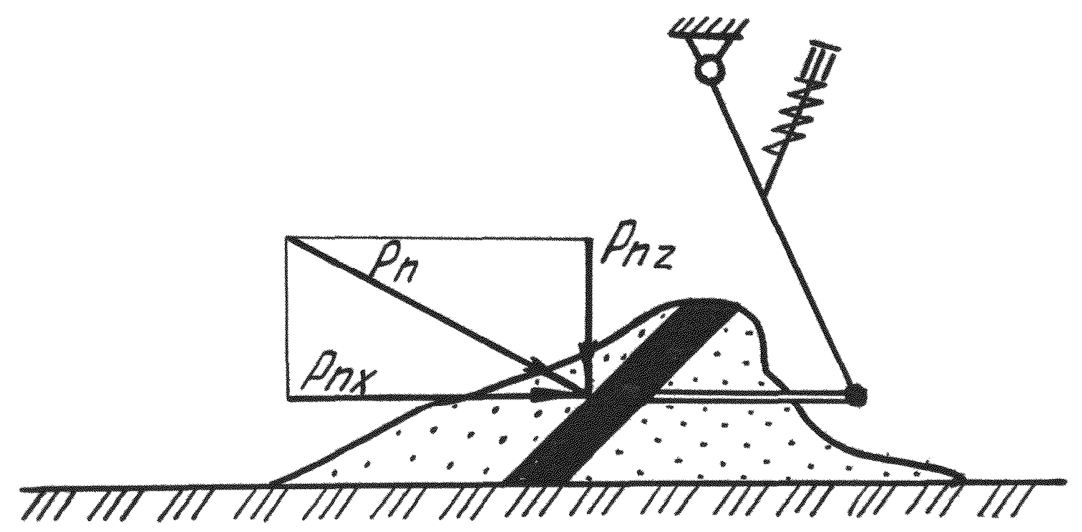

Fig. 1. Scheme for determining the resistance to movement of a passive knife.

On the crest of the channel dam (horizontal plane), the force will be equal

$$
P_{s h}=\mathrm{G}_{\mathrm{h}} \cdot \mathrm{f}_{1},
$$

where $f_{1}$ - soil friction coefficient.

The best condition for moving soil on channel slope in front of passive knife is its uniform distribution along the slope. In this case, on the channel slope, the force is

$$
P_{s s}=\mathrm{G}_{\mathrm{h}} \cdot \mathrm{f}_{1} \cdot \cos \lambda
$$

where $\lambda$ - slope pledging angle. 


\section{Resistance to trowel knife movement}

The working conditions of the trowel knife are characterized by a negative cutting angle $\alpha_{s r}$ . After mashing process stabilization, the knife 1 compacts a layer of various soil on slopes by an amount $h$ (Figure 2).

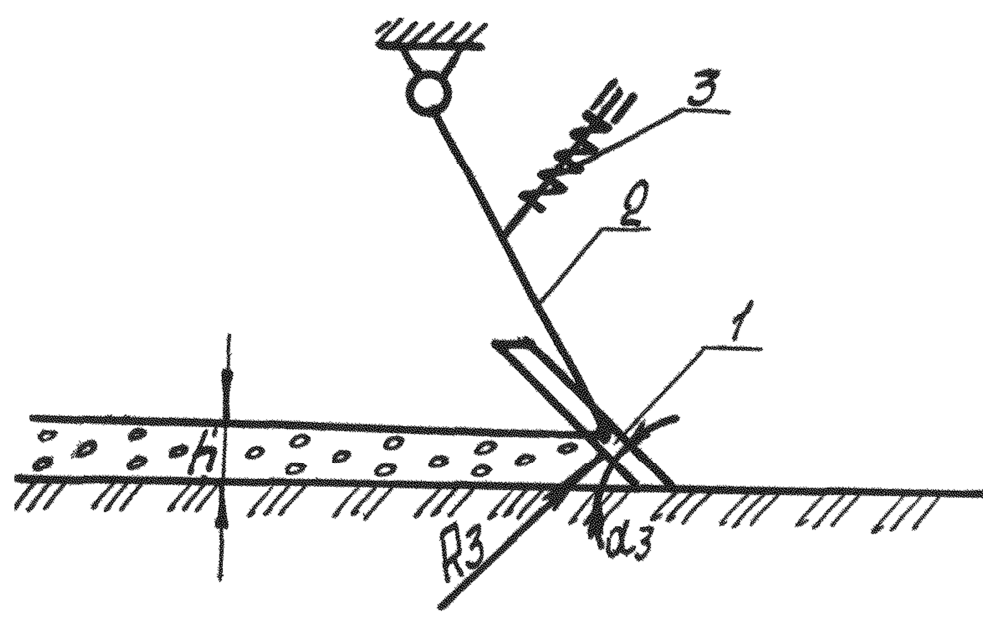

Fig. 2. Trowel knife installation diagram.

The force spent on compaction of loose soil $R_{s r}$ by layer $h$, can be determined if we accept the assumption that the loosened soil layer resistance during crushing is proportional to the strain value (Figure 3). In this case, the normal pressures plot on the trowel knife working surface will have the shape of a triangle

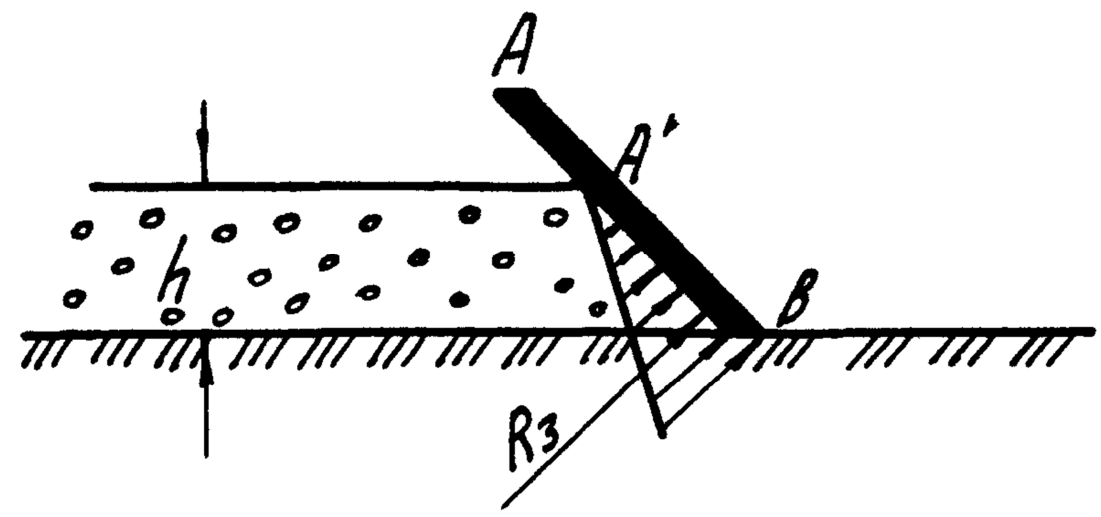

Fig. 3. Scheme for the determination of soil pressure on the trowel knife.

Maximum ground pressure $P$ at the point $B$ is

$$
P=K_{s r} \cdot h,
$$

where $K_{s r}$ - soil resistance to crushing.

Resultant $R_{s r}$ of elementary normal pressures during compaction of loosened soil layer on the trowel knife working surface at the point $B$ is 


$$
R_{s r}=\frac{\overline{A B} \cdot P \cdot b_{s r}}{2}
$$

where $b_{s r}-$ trowel knife width.

Since $A B=\frac{h}{\sin \alpha_{s r}}$, and $P=K_{s r} \cdot h$,

so

$$
R_{s r}=\frac{K_{s r} \cdot h^{2} \cdot b_{s r}}{2 \sin \alpha_{s r}}
$$

Magnitude of force $P_{s r}$ taking into account the trowel knife friction forces on the ground, it can be determined by assuming that $P_{s r}$ deviated from normal force $R_{s r}$ by angle $\varphi$ (Figure 4).

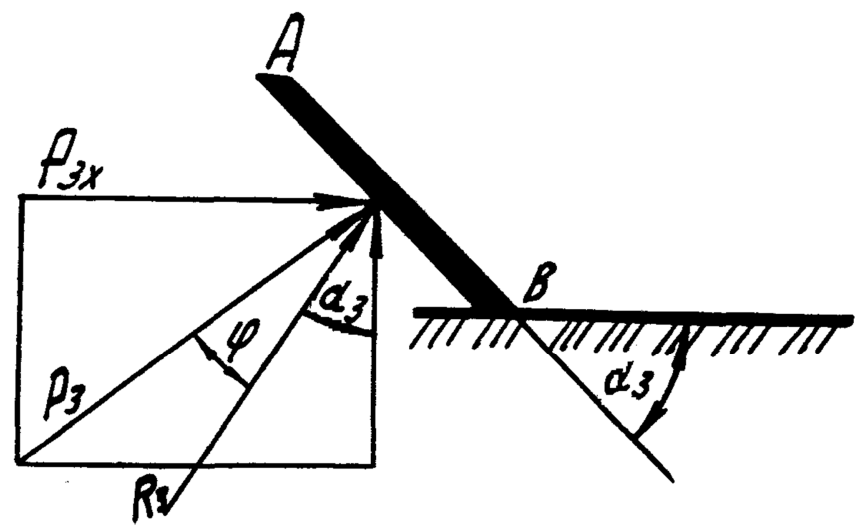

Fig. 4. Scheme to determine the effort spent for crushing soil with a trowel knife.

$$
P_{s r}=\frac{K_{s r} \cdot h^{2} \cdot b_{s r}}{2 \sin \alpha_{s r} \cdot \cos \varphi} .
$$

Vertical component $P_{s r z}$ and horizontal component $P_{s r x}$ of the resultant normal and tangential resistance forces due soil compaction with a trowel knife will be equal

$$
\begin{aligned}
& P_{s r z}=\frac{K_{s r} \cdot h^{2} \cdot b_{s r}}{2 \sin \alpha_{s r} \cdot \cos \varphi} \cdot \cos \left(\varphi+\alpha_{s r}\right) ; \\
& P_{s r x}=\frac{K_{s r} \cdot h^{2} \cdot b_{s r}}{2 \sin \alpha_{s r} \cdot \cos \varphi} \cdot \sin \left(\varphi+\alpha_{s r}\right) .
\end{aligned}
$$

From the last equation, it follows that by the magnitude of the force $P_{s x x}$ the most influence is exerted by the trowel knife installation value $\alpha_{s r}$ and the loosened soil thickness to be compacted.

It should be noted that it is possible to reduce the resistance to knives movement by applying solid lubricant coatings [15-29]. 


\section{Conclusions}

1. The necessary accuracy of channel profiling is provided when using machines capable of processing not only longitudinal but also channels' cross-sections.

2. The best moving soil condition on channel slope in front of the passive knife is its equable distribution along the slope.

3. The pressure magnitude is most affected by the trowel knife installation value and the loosened soil layer thickness to be compacted.

4. The developed materials can be recommended for use in the construction and operation of irrigation systems.

\section{References}

1. Yu.A. Ivanov, V.I. Pakhomov, S.I. Kambulov, D.V. Rudoi, MATEC Web of Conferences 224, 05023 (2018) https://doi.org/10.1051/matecconf/201822405023

2. A. Altybayev, A. Zhanbyrbayev, B. Meskhi, D. Rudoy, A. Olshevskaya, A. Prohorova, E3S Web of Conferences 135, 01078 (2019) https://doi.org/10.1051/e3sconf/201913501078

3. B. Meskhi, B. Golev, V. Efros, D. Rudoy, A. Olshevskaya, V. Zhurba, Y. Chayka, E3S Web of Conferences 135, 01083 (2019) https://doi.org/10.1051/e3sconf/201913501083

4. J. Gerber, A. Zavaly, A. Gavrilov, A. Olshevskaya, N. Kiyan, IOP Conf. Series: Earth and Environmental Science 403, 012014 (2019) doi:10.1088/1755-1315/403/1/012014

5. G. Parkhomenko, S. Kambulov, A. Olshevskaya, A. Babadzhanyan, N. Gucheva, I. Mekhantseva, IOP Conf. Series: Earth and Environmental Science 403, 012144 (2019) doi:10.1088/1755-1315/403/1/012144

6. Y. Lachuga, A. Soloviev, A. Matrosov, I. Panfilov, V. Pakhomov, D. Rudoy, IOP Conf. Series: Earth and Environmental Science 403, 012055 (2019) doi:10.1088/1755$1315 / 403 / 1 / 012055$

7. E. Zubrilina, I. Markvo, V. Novikov, A. Beskopylny, L. Vysochkina, D. Rudoy, A. Butovchenko, IOP Conf. Series: Earth and Environmental Science 403, 012063 (2019) doi:10.1088/1755-1315/403/1/012063

8. S.I. Kambulov, I.V. Bozhko, A.V. Olshevskaya, MATEC Web of Conferences 224, 05022 (2018) https://doi.org/10.1051/matecconf/201822405022

9. D. Evseev, A.Kotesova, V.era Kosenko, A. Golubeva, IOP Conference Series: Materials Science and Engineering 698, 066032 (2019)

10. V. Kasyanov, V. Deryushev, L. Shulkin, E. Kosenko, A. Kotesova, MATEC Web Conf. 224, 02107 (2018) doi.org/10.1051/matecconf/201822402107

11. V. Deryushev, M. Zaitseva, G. Megera, A. Fedyanov, IOP Conference Series: Materials Science and Engineering 698, 066031 (2019)

12. T. Rogovenko, M. Zaitseva, Materials Science Forum 931, 417-421 (2018) doi.org/10.4028/www.scientific.net/MSF.931.417

13. T. Rogovenko, M. Zaitseva, MATEC Web of Conference 106, 08011 (2017) doi.org/10.1051/matecconf/201610608011

14. T. Rogovenko, M. Zaitseva, MATEC Web of Conferences 129, 05014 (2017) doi.org/10.1051/matecconf/201712905014

15. A.A. Kostoglotov, D.S. Andrashitov, A.S. Kornev, S.V. Lazarenko, Measurement Techniques 62, 497-502 (2019) DOI: 10.1007/s11018-019-01652-8 
16. S.V. Lazarenko, A.A. Kostoglotov, Journal of Communications Technology and Electronics 62(2), 123-127 (2017) DOI: 10.1134/S1064226917020061

17. A.A. Kostoglotov, I.V. Pugachev, S.V. Lazarenko, AIP Conference Proceedings (2019) DOI: $10.1063 / 1.5138398$

18. A.A. Kostoglotov, I.V. Pugachev, A.A. Yachmenov, S.V. Lazarenko, Advances in Intelligent Systems and Computing 874, 116-124 (2019) DOI: 10.1007/978-3-03001818-4_12

19. S.V. Lazarenko, A.A. Kostoglotov, A.I. Kostoglotov, Journal of Communications Technology and Electronics 54(4), 431-438 (2009) DOI: 10.1134/S1064226909040081

20. V.V. Ivanov, S.I. Popov, E.M. Selemeneva, N.T. Babazhanov, AIP Conference Proceedings 2188, 020015 (2019) doi.org/10.1063/1.5138389

21. V.V. Ivanov, S.I. Popov, Ju.V. Marchenko, E.V. Marchenko, N.S. Dontsov, S.A. Timofeev, IOP Conference Series: Earth and Environmental Science 403, 012115 (2019) doi:10.1088/1755-1315/403/1/012115

22. A.A. Korotky, E.V. Marchenko, V.V. Ivanov, S.I. Popov, Ju.V. Marchenko, N.S. Dontsov, IOP Conference Series: Earth and Environmental Science 403, 012116 (2019) doi:10.1088/1755-1315/403/1/012116

23. A.A. Kotesova, S.V. Teplyakova, S.I. Popov, F.C. Kopylov, IOP Conference Series: Materials Science and Engineering 698, 066029 (2019) doi:10.1088/1757899X/698/6/066029

24. V.V. Ivanov, S.I. Popov, A.V. Kirichek, IOP Conference Series: Materials Science and Engineering 327, 032026 (2018) doi:10.1088/1757-899X/327/3/032026

25. V.V. Ivanov, N.S. Dontsov, A.V. Kirichek, IOP Conference Series: Materials Science and Engineering 327, 032025 (2018) doi:10.1088/1757-899X/327/3/032025

26. V.V. Ivanov, N.P. Pogorelov, N.S. Dontsov, Y.N. Denisenko, AIP Conference Proceedings 2188, 020005 (2019) doi.org/10.1063/1.5138379

27. N.N. Nikolaev, Yu.V. Marchenko, S.K. Filatov, IOP Conference Series: Materials Science and Engineering 698, 066027 (2019) doi:10.1088/1757-899X/698/6/066027

28. V.A. Lebedev, V.V. Ivanov, V.P. Fedorov, Materials Science and Engineering 124 (2016) doi.10.1088 / 1757-899X / 124/1/012160. R.1-6

29. V.P. Smolentsev, A.I. Portnykh, V.V. Ivanov, IOP Conf. Series: Materials Science and Engineering 327, 042121 (2018) doi: 10.1088 / 1757-899X / 327/4/042121 